\title{
Prevalence of left ventricular diastolic dysfunction by cardiac magnetic resonance imaging in thalassemia major patients with normal left ventricular systolic function
}

Benjaporn Chinprateep ${ }^{1}$, Nithima Ratanasit ${ }^{1}$, Yodying Kaolawanich', Khemajira Karaketklang²,

Pairash Saiviroonporn ${ }^{3}$, Vip Viprakasit ${ }^{4}$ and Rungroj Krittayaphong ${ }^{1 *}$ (D)

\begin{abstract}
Background: The leading cause of mortality of thalassemia major patients is iron overload cardiomyopathy. Early diagnosis with searching for left ventricular diastolic dysfunction before the systolic dysfunction ensued might yield better prognosis. This study aimed to define the prevalence of the left ventricular diastolic dysfunction (LVDD) in thalassemia major patients with normal left ventricular systolic function and the associated factors.

Methods: Adult thalassemia major patients with normal left ventricular systolic function who were referred for cardiac T2* at Siriraj Hospital - Thailand's largest national tertiary referral center - during the October 2014 to January 2017 study period. Left ventricular diastolic function was defined by mitral valve filling parameters and left atrial volume index using CMR. Patients with moderate to severe valvular heart disease, pericardial disease, or incomplete data were excluded. Baseline characteristics, comorbid diseases, current medication, and laboratory results were recorded and analyzed.

Results: One hundred and sixteen patients were included, with a mean age of $27.5 \pm 13.5$ years, $57.8 \%$ were female, and $87.9 \%$ were transfusion dependent. Proportions of homozygous beta-thalassemia and beta-thalassemia hemoglobin E were 12.1 and $87.9 \%$, respectively. The baseline hematocrit was $26.3 \pm 3.3 \%$. The prevalence of LVDD was 20.7\% (95\% Cl: 13.7-29.2\%). Cardiac T2* was abnormal in 7.8\% (95\% Cl: 3.6-14.2\%). Multivariate analysis revealed age, body surface area, homozygous beta-thalassemia, splenectomy, heart rate, and diastolic blood pressure to be significantly associated with LVDD.

Conclusions: LVDD already exists from the early stages of the disease before the abnormal heart $\mathrm{T} 2{ }^{*}$ is detected. Homozygous beta-thalassemia and splenectomy were strong predictors of LVDD. These data may increase awareness of the disease, especially in the high risk groups.
\end{abstract}

Keywords: Thalassemia, Left ventricular diastolic dysfunction, Left ventricular diastolic dysfunction, Cardiac magnetic resonance imaging

\footnotetext{
* Correspondence: rungroj.kri@mahidol.ac.th

${ }^{1}$ Division of Cardiology, Department of Medicine, Faculty of Medicine, Siriraj

Hospital, Mahidol University, 2 Wanglang Road, Bangkoknoi, Bangkok 10700,

Thailand

Full list of author information is available at the end of the article
}

(c) The Author(s). 2019 Open Access This article is distributed under the terms of the Creative Commons Attribution 4.0 International License (http://creativecommons.org/licenses/by/4.0/), which permits unrestricted use, distribution, and reproduction in any medium, provided you give appropriate credit to the original author(s) and the source, provide a link to the Creative Commons license, and indicate if changes were made. The Creative Commons Public Domain Dedication waiver (http://creativecommons.org/publicdomain/zero/1.0/) applies to the data made available in this article, unless otherwise stated. 


\section{Introduction}

The leading cause of mortality of thalassemia major patients is iron overload cardiomyopathy. Since current diagnosis is made by evaluation of $\mathrm{T} 2 \%$ by cardiac magnetic resonance (CMR) imaging [1], the myocardium is already involved by the iron. Some patients are detected in late of the disease with impaired left ventricular systolic function, and unfavorable outcomes. Previous studies in iron overload cardiomyopathy found left ventricular diastolic dysfunction could be detected before the systolic dysfunction ensued [2]. And in other diseases, such as coronary artery disease and heart failure, diastolic dysfunction was reported to be associated with increased morbidity and mortality [3-5]. Thus, left ventricular diastolic function is important for early detection of the disease and treatment, along with better prognosis.

Previous studies of left ventricular diastolic function in thalassemia major patients have various in results in prevalence and associated factors [6-10]. The reported prevalence of LVDD ranged widely from 7.9 to $100 \%$, and most cases demonstrated restrictive filling pattern $[8,9,11]$. The prevalence of iron overload cardiomyopathy also varied depending on the standard of care that the patients received in that region and the era of the report. The prevalence could be more than $50 \%$ in some previous reports $[9,12]$. In the tertiary-care setting with well-controlled iron chelation therapy in the current era and available CMR system for the detection and assessment of cardiac involvement, the prevalence of cardiac iron overload may be less than $10 \%$ [13]. Left ventricular diastolic dysfunction usually precede systolic dysfunction and heart failure [2]. Left ventricular diastolic dysfunction cannot be completely explained by cardiac iron overload since previous data indicated that parameters for mitral valve filling were not well correlated with cardiac $\mathrm{T} 2 *$ [10] and chelation treatment did not completely protect patients from left ventricular diastolic and systolic dysfunction [8]. Previous study showed that left ventricular diastolic function can be improved by medication in patients with thalassemia [14]. Most of the studies used echocardiogram for evaluation of the left ventricular diastolic function. Biomarker such as brain natriuretic peptide can detect early cardiac involvement in thalassemia patients but it may not be cost effective to use as a screening [15]. While current diagnosis of cardiac involvement by the iron overload is done by CMR and many patients were requested to undergo CMR without echocardiogram. Parameters for assessment of diastolic function by CMR has been shown to be well correlated with echocardiographic parameters [16]. This study aimed to define the prevalence of left ventricular diastolic dysfunction (LVDD) in thalassemia major patients with normal left ventricular systolic function. The associated factors of LVDD was also analyzed. In this study, CMR parameters were used for the assessment of left ventricular diastolic function.

\section{Patients and methods \\ Study population}

The study protocol was approved by the Siriraj Institutional Review Board of the Faculty of Medicine Siriraj Hospital, Mahidol University, Bangkok Thailand, and all patients provided written informed consent to participate. Adult thalassemia major patients (age $\geq 18$ years) with normal LV systolic function (LV ejection fraction $\geq 55 \%$ by CMR [17]) who were evaluated for cardiac T2* at Siriraj Hospital during 1 October 2014 to 4 January 2017 were included. Patients with moderate to severe valvular heart disease, pericardial disease, contraindication for magnetic resonance imaging (MRI) or claustrophobia, or incomplete data were excluded. Patient data was retrieved from electronic medical records and from the CMR database. Baseline characteristics, comorbid diseases, current medication, and laboratory results were recorded and analyzed.

\section{Cardiac magnetic resonance (CMR) imaging technique}

Cardiac function and $\mathrm{T} 2 *$ were performed on a $1.5 \mathrm{~T}$ Achieva-XR Quasar-Dual-Gradient System (Philips Medical Systems, Best, The Netherlands) with a 5-element cardiac coil. Steady-state free precession, breath-hold technique was performed for cardiac function evaluation. For cardiac function, cines of 4-chamber, 2-chamber, and short-axis views from apex to atrioventricular valve ring were acquired. The CMR parameters were, as follows: 8 $\mathrm{mm}$ slice thickness for 10-12 slices without gap in between, repetition time (TR) $3.4 \mathrm{~ms}$, echo time (TE) $1.7 \mathrm{~ms}$, and flip angle $60^{\circ}$. LV ejection fraction (LVEF), LV enddiastolic volume (LVEDV), LV systolic volume (LVSV), and LV mass were calculated as previously described by Krittayaphong, et al. [17]. Left atrial (LA) volume was calculated by area-length method [18]. Two-chamber and four-chamber views were used. The LA area was contoured at the end systole, but the left atrial appendage and pulmonary veins were excluded. LA length was drawn from the midpoint of the mitral annulus to the opposite LA wall (Fig. 1). LA volume was calculated using the following formula:

LA volume $=0.85 \times$ LA area (2-chamber view) $\times$ LA area (4-chamber view)/LA length.

(The shortest LA length from the 2-chamber view and 4-chamber view was used in the formula)

Cardiac T2* was performed with gradient-echo, black blood technique. Single short-axis mid-ventricular slice with 8 TE from $2.60-16.74 \mathrm{~ms}$ with each step of $2.02 \mathrm{~ms}$ was used. CMR parameters for T2* were, as follows: slice thickness $10 \mathrm{~mm}$, TR $18 \mathrm{~ms}$, flip angle $20^{\circ}$, field of view 


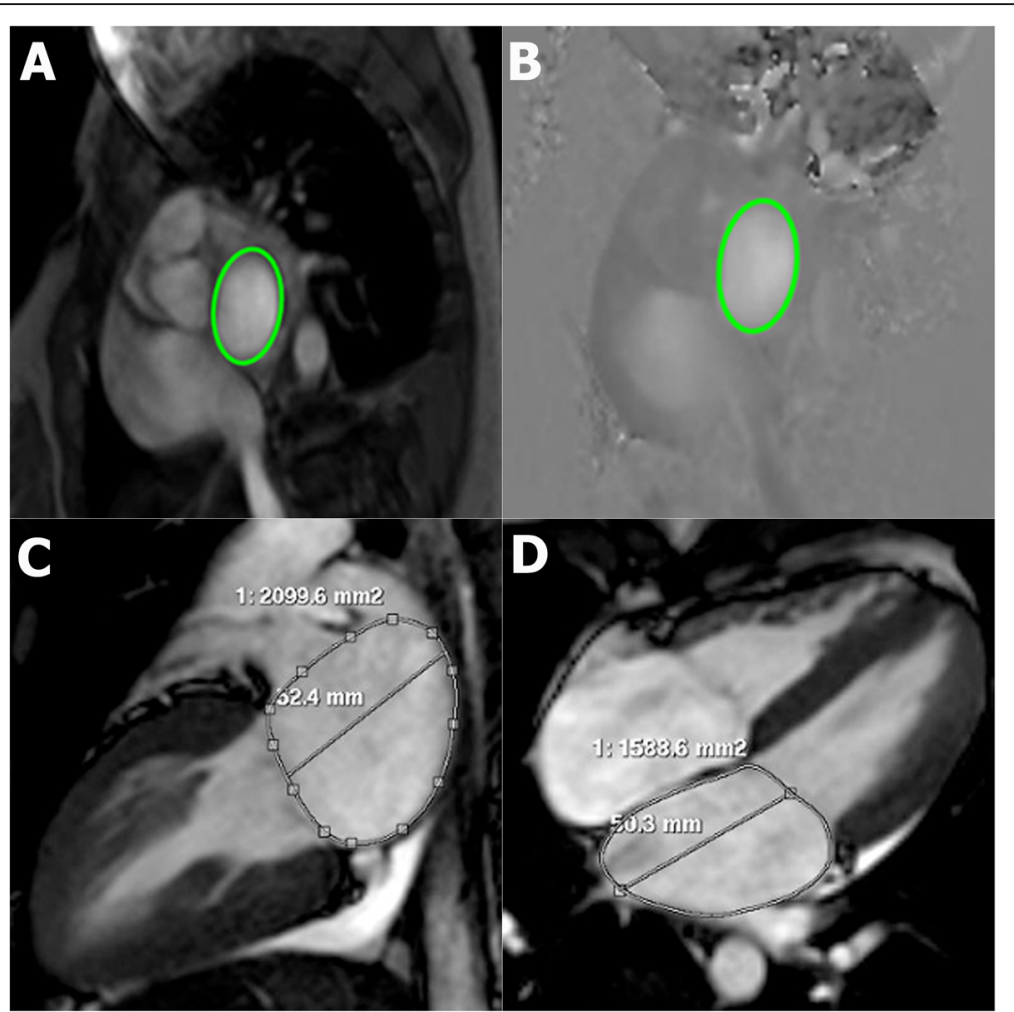

Fig. 1 CMR technique - two-dimensional phase contrast imaging at mitral annular plane. Region of interest was drawn from magnitude image (a), flow and peak velocity were calculated from phase image (b). Mitral velocity-time curve yielded E, A, and DT, which represented the time from peak of $E$ wave to the point intersected by the downslope line drawn from peak of $E$ wave. Left atrial (LA) volume was calculated by arealength method in two-chamber (c) and four-chamber (d) views. The LA area was contoured at the end systole, but the left atrial appendage and pulmonary veins were excluded. LA length was drawn from midpoint of the mitral annulus to the opposite LA wall

(FOV) $400 \times 400 \mathrm{~mm}$, and voxel size $3.0 \times 1.5 \times 10 \mathrm{~mm}^{3}$. The 8 images were quantitatively analyzed by pixel-wise method for all segments, and then the septum was chosen. The median $\mathrm{T} 2 *$ value was reported as abnormal if the T2* was $\leq 20 \mathrm{~ms}$. This method was well-validated and had good reproducibility [19-23]. Diastolic function was analyzed from velocity-time curve and volume-time curve at mitral valve inflow on the mitral annular plane, which was derived from the cross-sectional line of mitral annulus in 4-chamber and 2-chamber view at enddiastolic phase. Two-dimensional phase contrast imaging at the mitral annular plane with retrospective ECG gating was analyzed. The parameters were TR $6.1 \mathrm{~ms}$, TE $3.7 \mathrm{~ms}$, slice thickness $8 \mathrm{~mm}$ without gap between slices, flip angle $12^{\circ}$, FOV $320 \times 320 \mathrm{~mm}$, included 40 phases per a cardiac cycle, and velocity encoding $100 \mathrm{~cm} / \mathrm{s}$. Region of interest was drawn from magnitude image, and flow and peak velocity were calculated from phase image (Fig. 1). The mitral volume-time curve yielded early peak filling rate (EPFR) and late peak filling rate (LPFR), and the velocity-time curve yielded early diastolic filling velocity (E), late diastolic filling velocity (A), and deceleration time (DT), which is the time from peak of $\mathrm{E}$ wave to baseline. The method was adapted from previous study, which showed good correlation with echocardiographic parameters [24-27].

We use CMR, not echocardiography, to determine LVDD in the present study. The criteria for LVDD was modified from the ASE 2009 criteria [28], which focused on parameters on mitral valve filling, and LAVI as suggested by the ASE 2016 criteria [29]. LV diastolic function was defined as abnormal relaxation if $\mathrm{E} / \mathrm{A}$ ratio $\leq$ 0.8 and $\mathrm{E} \leq 50 \mathrm{~cm} / \mathrm{s}$, or as restrictive filling pattern if $\mathrm{E} / \mathrm{A}$ ratio $>2$ and $\mathrm{DT}<160 \mathrm{~ms}$ or $\mathrm{DT}>160 \mathrm{~ms}$ with $\mathrm{E}>120$ $\mathrm{cm} / \mathrm{s}$. Left atrial volume index (LAVI) was used to further classify diastolic function in selected patients as shown in Fig. 2 [30]. If the LAVI was abnormally high $\left(>74 \mathrm{ml} / \mathrm{m}^{2}\right.$ in female, and $>71 \mathrm{ml} / \mathrm{m}^{2}$ in male) [18], pseudonormalization of LV diastolic function was diagnosed.

\section{Statistical analysis}

Baseline characteristics were summarized using descriptive statistics. Frequency and percentage were used to describe categorical variables. Continuous variables were reported as mean \pm standard deviation for normally 


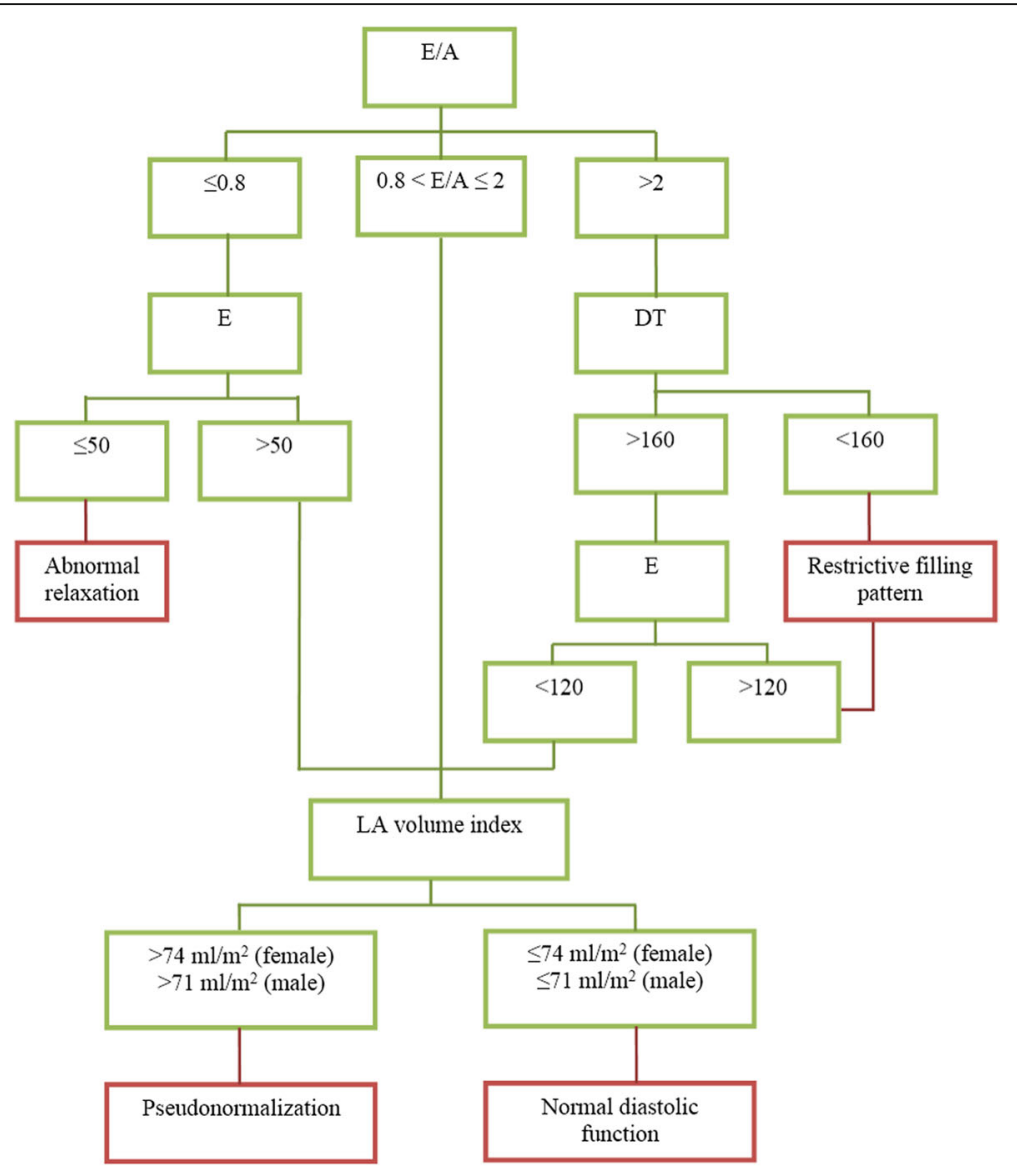

Fig. 2 Left ventricular diastolic function was defined as abnormal relaxation or restrictive filling pattern by the condition described. If it could not be determined, left atrial volume index was used to define pseudonormalization or normal diastolic function. E velocity=early diastolic filling velocity, $E / A=E / A$ ratio, $D T=$ deceleration time, $L A=$ left atrial

distributed variables, and as median and interquartile range (25th and 75th percentile) for non-normally distributed variables. Kolmogorov-Smirnov test was used to evaluate for normal distribution. The prevalence of LVDD is described as percentage and 95\% confidence interval. Association between continuous variables and LVDD was determined using Student's $t$-test or MannWhitney U test. For categorical variables, chi-square test or Fisher's exact test was used to test for association. Variables associated with LVDD at a $p$-value less than 0.2 were entered into univariate analysis. Variables found to be significantly associated with LVDD in univariate analysis were entered into multivariate analysis using forward stepwise multiple logistic regression.

Intraclass correlation coefficient (ICC) was performed in 10 patients to measure intraobserver and interobserver reliability. For all tests performed, a two-tailed $p$ value $<0.05$ was considered to denote statistical significance. The statistical software package SPSS (version 18; SPSS, Inc., Chicago, IL, USA) was employed for all data analyses.

\section{Results}

There were 123 patients eligible for inclusion during the 1 October 2014 to 4 January 2017 study period. However, diastolic function could not be interpreted in 7 patients due to absence of $\mathrm{A}$ or fusion of $\mathrm{E}$ and $\mathrm{A}$ waves, so those patients were excluded from the study. The remaining 116 patients were enrolled. Baseline characteristics of study population were shown in Table 1 . Cardiac magnetic resonance imaging parameters of study population were compared between normal diastolic function group and diastolic dysfunction group as in Table 2.

The prevalence of LVDD was $20.7 \%$ (95\% CI: $13.7-$ 29.2\%). Abnormal relaxation, pseudonormalization, and restrictive filling pattern was found in 3 (13\%), 7 (29\%), and $14(58 \%)$ patients, respectively. Cardiac $\mathrm{T} 2 *$ was abnormal in $8.3 \%$ (95\% CI: $1.0-27.0 \%)$ of patients in the LVDD group, and in 7.8\% (95\% CI: 3.6-14.2\%) of all patients enrolled in this study.

Univariate and multivariate analysis was performed to assess for factors significantly associated with LVDD 
Table 1 Baseline characteristics of study population

\begin{tabular}{|c|c|c|c|c|}
\hline Variables & Total $(n=116)$ & Normal diastolic function $(n=92)$ & Diastolic dysfunction $(n=24)$ & $p$-value \\
\hline Age (years) & $27.46 \pm 13.52$ & $26.13 \pm 10.17$ & $32.54 \pm 21.70$ & 0.171 \\
\hline Female gender & $67(57.76 \%)$ & $54(58.70 \%)$ & $13(54.17 \%)$ & 0.689 \\
\hline Body weight (kg) & $47.46 \pm 10.02$ & $48.28 \pm 10.38$ & $44.29 \pm 7.91$ & 0.082 \\
\hline Body surface area $\left(\mathrm{m}^{2}\right)$ & $1.43 \pm 0.19$ & $1.44 \pm 0.20$ & $1.37 \pm 0.16$ & 0.101 \\
\hline $\mathrm{SBP}(\mathrm{mmHg})$ & $109.62 \pm 14.88$ & $109.97 \pm 12.51$ & $108.29 \pm 22.04$ & 0.723 \\
\hline $\mathrm{DBP}(\mathrm{mmHg})$ & $61.56 \pm 11.50$ & $62.89 \pm 11.23$ & $56.46 \pm 11.32$ & 0.014 \\
\hline Heart rate (bpm) & $83.11 \pm 11.72$ & $84.80 \pm 11.85$ & $76.63 \pm 8.65$ & 0.002 \\
\hline Homozygous beta thalassemia & $14(12.07 \%)$ & $7(7.61 \%)$ & $7(29.17 \%)$ & 0.009 \\
\hline Hemoglobin E/beta thalassemia & $102(87.93 \%)$ & 85 (92.39\%) & $17(70.83 \%)$ & 0.009 \\
\hline Splenectomy $(n=116)$ & $28(24.13 \%)$ & $18(19.56 \%)$ & $10(41.67 \%)$ & 0.026 \\
\hline Transfusion dependent & 95 (81.90\%) & 77 (83.70\%) & $18(75.00 \%)$ & 0.374 \\
\hline Total transfusion in 1 year (ml); median (IQR) & $\begin{array}{l}175.41 \pm 61.13 \\
4(4-4)\end{array}$ & $\begin{array}{l}177.74 \pm 64.40 \\
4(4-4)\end{array}$ & $\begin{array}{l}176.63 \pm 45.90 \\
4(3-4)\end{array}$ & 0.944 \\
\hline Diabetes mellitus & $11(9.48 \%)$ & $8(8.70 \%)$ & $3(12.50 \%)$ & 0.695 \\
\hline Hypothyroidism & $11(9.48 \%)$ & $7(7.61 \%)$ & $4(16.67 \%)$ & 0.235 \\
\hline Hypertension & $1(0.86 \%)$ & $0(0.00 \%)$ & $1(4.17 \%)$ & 0.207 \\
\hline \multicolumn{5}{|l|}{ Medication use } \\
\hline - Deferiprone & $57(49.14 \%)$ & $46(50.00 \%)$ & $11(45.83 \%)$ & 0.716 \\
\hline - Deferasirox & $43(37.07 \%)$ & $33(35.87 \%)$ & $10(41.67 \%)$ & 0.601 \\
\hline - Deferoxamine & $39(33.62 \%)$ & $34(36.97 \%)$ & $5(20.83 \%)$ & 0.136 \\
\hline - Beta blockers & $7(6.03 \%)$ & $4(4.35 \%)$ & $3(12.50 \%)$ & 0.154 \\
\hline - ACEI/ARB & $2(1.72 \%)$ & $1(1.09 \%)$ & $1(4.17 \%)$ & 0.372 \\
\hline - Statin & $2(1.72 \%)$ & $1(1.09 \%)$ & $1(4.17 \%)$ & 0.372 \\
\hline - Diuretics & $2(1.72 \%)$ & $1(1.09 \%)$ & $1(4.17 \%)$ & 0.372 \\
\hline - Aspirin & $14(12.07 \%)$ & $10(10.87 \%)$ & $4(16.67 \%)$ & 0.484 \\
\hline Hemoglobin (g/dl) & $8.48 \pm 1.21$ & $8.53 \pm 1.20$ & $8.28 \pm 1.27$ & 0.361 \\
\hline Hematocrit & $26.33 \pm 3.26$ & $26.44 \pm 3.22$ & $25.89 \pm 3.44$ & 0.467 \\
\hline Creatinine (mg/dl) & $0.64 \pm 0.17$ & $0.64 \pm 0.17$ & $0.66 \pm 0.17$ & 0.462 \\
\hline Ferritin (mcg/l) & $1440.0(678.0-2575.50)$ & $1411.00(596.00-2411.00)$ & $1502.50(824.50-2694.00)$ & 0.424 \\
\hline Liver iron concentration (mg Fe/g dry weight) & $7.40(3.65-15.45)$ & $7.15(2.95-14.55)$ & $8.30(4.90-23.75)$ & 0.116 \\
\hline
\end{tabular}

A $p$-value $<0.05$ indicates statistical significance (bold and italic)

Data presented as mean \pm standard deviation, median and interquartile range (IQR, 25th-75th percentile), or number and percentage

Abbreviations: SBP Systolic blood pressure, DBP Diastolic blood pressure, bpm Beats per minute, $A C E I / A R B$ Angiotensin converting enzyme inhibitor/angiotensin receptor blocker, Fe Iron

(Table 3). Age, body surface area (BSA), type of thalassemia (homozygous beta thalassemia), splenectomy, use of deferoxamine, heart rate (HR), diastolic blood pressure (DBP), and liver iron concentration were found to be univariately associated with LVDD. Factors found to be associated with LVDD in multivariate analysis were age (odds ratio [OR]: 1.07, 95\% confidence interval [CI]: 1.02-1.12; $p=0.004)$, BSA (OR: 0.01, 95\% CI: 0.0001-0.24; $p=0.005$ ), homozygous beta-thalassemia (OR: 6.26, 95\% CI: 1.38-28.39; $p=$ 0.017), splenectomy (OR: $4.53,95 \%$ CI: $1.29-15.93 ; p=$ 0.018 ), HR (OR: 0.92, 95\% CI: 0.87-0.98; $p=0.008$ ), and DBP (OR: 0.94, 95\% CI: 0.89-0.99; $p=0.044$ ).
Intraobserver and interobserver reliability was demonstrated by ICC, and the parameters were found to be well correlated (Table 4). All parameters were in good correlation.

We used CMR, not TTE, to determine LVDD in the present study. Therefore, we did not have data on TTE in every case. Additional analysis was performed to correlate CMR finding on diastolic dysfunction with TTE data among those who had available TTE results within 6 months prior to CMR examination. We demonstrated a good agreement of echocardiogram and CMR for the detection and correctly classified the grading of diastolic 
Table 2 Cardiac magnetic resonance imaging parameters of study population

\begin{tabular}{|c|c|c|c|c|}
\hline Variables & Total $(n=116)$ & Normal diastolic function $(n=92)$ & Diastolic dysfunction $(n=24)$ & $p$-value \\
\hline LVEF (\%) & $63.59 \pm 4.67$ & $63.66 \pm 4.47$ & $63.33 \pm 5.47$ & 0.765 \\
\hline LVEDV (ml) & $135.63 \pm 34.15$ & $132.17 \pm 30.79$ & $148.45 \pm 43.12$ & 0.093 \\
\hline LVESV (ml) & $49.43 \pm 14.20$ & $47.88 \pm 12.09$ & $55.39 \pm 19.81$ & 0.087 \\
\hline LVMI $\left(\mathrm{g} / \mathrm{m}^{2}\right)$ & $50.87 \pm 13.40$ & $49.52 \pm 12.72$ & $56.02 \pm 14.91$ & 0.034 \\
\hline LA area $2 \mathrm{ch}\left(\mathrm{mm}^{2}\right)$ & $18.38 \pm 4.61$ & $17.64 \pm 3.73$ & $21.21 \pm 6.38$ & 0.014 \\
\hline LA length 2ch (mm) & $45.01 \pm 6.11$ & $44.33 \pm 5.42$ & $47.63 \pm 7.83$ & 0.018 \\
\hline LA area $4 \mathrm{ch}\left(\mathrm{mm}^{2}\right)$ & $20.59 \pm 4.74$ & $19.73 \pm 3.84$ & $23.92 \pm 6.30$ & 0.004 \\
\hline LA length 4ch (mm) & $54.17 \pm 6.79$ & $53.11 \pm 5.88$ & $58.25 \pm 8.48$ & 0.009 \\
\hline LAVI $\left(\mathrm{ml} / \mathrm{m}^{2}\right)$ & $50.37 \pm 16.27$ & $46.27 \pm 10.48$ & $66.06 \pm 23.76$ & 0.001 \\
\hline $\operatorname{EPFR}(\mathrm{ml} / \mathrm{s})$ & $383.26 \pm 94.41$ & $375.97 \pm 82.55$ & $411.19 \pm 128.75$ & 0.213 \\
\hline $\operatorname{LPFR}(\mathrm{ml} / \mathrm{s})$ & $210.30 \pm 62.23$ & $211.34 \pm 59.56$ & $206.31 \pm 72.85$ & 0.726 \\
\hline E velocity $(\mathrm{cm} / \mathrm{s})$ & $61.76 \pm 11.74$ & $61.38 \pm 10.86$ & $63.23 \pm 14.83$ & 0.493 \\
\hline A velocity $(\mathrm{cm} / \mathrm{s})$ & $42.21 \pm 13.43$ & $43.17 \pm 13.96$ & $38.54 \pm 10.60$ & 0.133 \\
\hline$E / A$ & $1.55 \pm 0.42$ & $1.49 \pm 0.33$ & $1.78 \pm 0.60$ & 0.035 \\
\hline Deceleration time (ms) & $147.34 \pm 32.95$ & $147.94 \pm 30.55$ & $145.02 \pm 41.58$ & 0.701 \\
\hline Cardiac T2* (ms) & $36.46 \pm 8.96$ & $36.65 \pm 8.53$ & $35.71 \pm 10.61$ & 0.649 \\
\hline Abnormal cardiac T2* $(<20 \mathrm{~ms})$ & $9(7.76 \%)$ & $7(7.61 \%)$ & $2(8.33 \%)$ & 1.00 \\
\hline
\end{tabular}

A $p$-value $<0.05$ indicates statistical significance (bold and italic)

Data presented as mean \pm standard deviation or number and percentage

Abbreviations: LVEF Left ventricular ejection fraction, LVEDV Left ventricular end-diastolic volume, LVESV Left ventricular end-systolic volume, LVMI Left ventricular mass index, LA area 2ch Left atrial area from 2-chamber view, LA length 2ch Left atrial length from 2-chamber view, LA area 4ch Left atrial area from 4-chamber view, $L A$ length $4 c h$ Left atrial length from 4-chamber view, LAVI Left atrial volume index, EPFR Early peak filling rate, LPFR Late peak filling rate, $E$ velocity Early diastolic filling velocity, $A$ velocity Late atrial systolic filling velocity, E/A E/A ratio

dysfunction in 17 patients (89.5\%). Restrictive filling which is the most severe form of diastolic dysfunction was correctly detected in $100 \%$.

\section{Discussion}

The prevalence of LVDD in thalassemia major patients with normal LV systolic function in this study was $21.4 \%$. Factors associated with LV diastolic dysfunction in multivariate analysis were age, BSA, DBP, HR, homozygous beta thalassemia, and splenectomy.
Previous studies showed that LVDD may relate to changes that occur in the early stage of cardiac iron overload, and that these changes may be detectable before systolic failure. The prevalence of LVDD in our study was more than that reported by Kremastinos, et al. [7], but less than that reported by Spirito, et al. [8] and Leonardi, et al. [9]. In the Kremastinos, et al. study [7], diastolic function by transthoracic echocardiograpgy (TTE) was compared between 88 beta-thalassemia major patients with normal LV systolic function and 46 normal

Table 3 Univariate and multivariate analysis for factors associated with LV diastolic dysfunction

\begin{tabular}{|c|c|c|c|c|}
\hline \multirow[t]{2}{*}{ Factors } & Univariate & \multirow{2}{*}{$\begin{array}{l}p- \\
\text { value }\end{array}$} & Multivariate & \multirow{2}{*}{$\begin{array}{l}p- \\
\text { value }\end{array}$} \\
\hline & Crude OR $(95 \% \mathrm{Cl})$ & & Adjusted OR $(95 \% \mathrm{Cl})$ & \\
\hline Age & $1.03(1.00-1.06)$ & 0.050 & $1.07(1.02-1.12)$ & 0.004 \\
\hline Body surface area & $0.15(0.02-1.52)$ & 0.108 & $0.01(0.0001-0.24)$ & 0.005 \\
\hline Splenectomy & $2.90(1.11-7.68)$ & 0.030 & $4.53(1.29-15.93)$ & 0.018 \\
\hline Homozygous beta-thalassemia & $5.00(1.55-16.11)$ & 0.007 & $6.26(1.38-28.39)$ & 0.017 \\
\hline Deferoxamine & $0.45(0.15-1.31)$ & 0.143 & - & - \\
\hline Beta blocker & $3.14(0.65-15.12)$ & 0.153 & - & - \\
\hline Heart rate & $0.93(0.89-0.98)$ & 0.003 & $0.92(0.87-0.98)$ & 0.008 \\
\hline Liver iron concentration & $1.03(0.99-1.07)$ & 0.173 & - & - \\
\hline Diastolic blood pressure & $0.95(0.90-0.99)$ & 0.017 & $0.94(0.89-0.99)$ & 0.044 \\
\hline
\end{tabular}

A $p$-value $<0.05$ indicates statistical significance (bold and italic) 
Table 4 Intraclass correlation coefficient $(n=10)$

\begin{tabular}{|c|c|c|c|c|c|c|c|}
\hline \multirow[t]{2}{*}{ Variable } & \multirow{2}{*}{$\begin{array}{l}\text { Time } 1 \\
\text { Mean } \pm \text { SD }\end{array}$} & \multirow{2}{*}{$\begin{array}{l}\text { Time } 2 \\
\text { Mean } \pm \text { SD }\end{array}$} & \multirow{2}{*}{$\begin{array}{l}\text { Person } 2 \\
\text { Mean } \pm \text { SD }\end{array}$} & Intraobserver & \multirow[t]{2}{*}{$p$-value } & Interobserver & \multirow[t]{2}{*}{$p$-value } \\
\hline & & & & Time 1 vs. Time 2 & & Person 1 vs. Person 2 & \\
\hline $\operatorname{EPFR}(\mathrm{ml} / \mathrm{s})$ & $412.4 \pm 105.4$ & $433.6 \pm 102.3$ & $448.7 \pm 104.9$ & $0.99(0.97-0.99)$ & $<0.001$ & $0.97(0.87-0.99)$ & $<0.001$ \\
\hline LPFR (ml/s) & $224.0 \pm 73.8$ & $224.9 \pm 80.2$ & $239.3 \pm 81.7$ & $0.99(0.98-0.99)$ & $<0.001$ & $0.97(0.87-0.99)$ & $<0.001$ \\
\hline DT (ms) & $159.2 \pm 25.8$ & $160.4 \pm 27.5$ & $161.4 \pm 26.6$ & $0.97(0.86-0.99)$ & $<0.001$ & $0.94(0.77-0.99)$ & $<0.001$ \\
\hline E velocity $(\mathrm{cm} / \mathrm{s})$ & $67.6 \pm 12.4$ & $67.6 \pm 12.4$ & $67.6 \pm 12.4$ & $1(1-1)$ & NA & $1(1-1)$ & NA \\
\hline A velocity $(\mathrm{cm} / \mathrm{s})$ & $44.7 \pm 12.5$ & $44.7 \pm 12.5$ & $44.7 \pm 12.5$ & $1(1-1)$ & NA & $1(1-1)$ & NA \\
\hline E/A & $1.6 \pm 0.6$ & $1.6 \pm 0.6$ & $1.6 \pm 0.6$ & $1(1-1)$ & NA & $1(1-1)$ & NA \\
\hline LA area $2 \mathrm{ch}\left(\mathrm{mm}^{2}\right)$ & $18.2 \pm 3.6$ & $18.7 \pm 3.9$ & $18.5 \pm 3.6$ & $0.98(0.93-0.99)$ & $<0.001$ & $0.97(0.89-0.99)$ & $<0.001$ \\
\hline LA length 2ch (mm) & $45.0 \pm 5.4$ & $44.9 \pm 4.9$ & $45.0 \pm 5.6$ & $0.95(0.80-0.99)$ & $<0.001$ & $0.86(0.55-0.96)$ & $<0.001$ \\
\hline LA area $4 \mathrm{ch}\left(\mathrm{mm}^{2}\right)$ & $21.6 \pm 5.5$ & $22.1 \pm 5.1$ & $22.4 \pm 4.8$ & $0.98(0.92-0.99)$ & $<0.001$ & $0.98(0.92-0.99)$ & $<0.001$ \\
\hline LA length 2ch (mm) & $55.1 \pm 8.1$ & $56.7 \pm 8.0$ & $51.2 \pm 6.6$ & $0.93(0.73-0.98)$ & $<0.001$ & $0.88(0.60-0.97)$ & $<0.001$ \\
\hline LA vol (ml) & $75.3 \pm 25.8$ & $79.2 \pm 79.4$ & $79.4 \pm 23.5$ & $0.98(0.91-0.99)$ & $<0.001$ & $0.97(0.90-0.99)$ & $<0.001$ \\
\hline LAVI $\left(\mathrm{ml} / \mathrm{m}^{2}\right)$ & $50.0 \pm 15.0$ & $52.5 \pm 15.5$ & $52.8 \pm 13.3$ & $0.97(0.89-0.99)$ & $<0.001$ & $0.99(0.87-0.99)$ & $<0.001$ \\
\hline
\end{tabular}

A $p$-value $<0.05$ indicates statistical significance (bold and italic)

Intraclass correlation coefficient (ICC) and 95\% confidence interval

Abbreviations: EPFR Early peak filling rate, LPFR Late peak filling rate, DT Deceleration time, E velocity Early diastolic filling velocity, $A$ velocity Late atrial systolic filling velocity, E/A E/A ratio, LA area $2 \mathrm{ch}$ Left atrial area from 2-chamber view, LA length $2 \mathrm{ch}$ Left atrial length from 2 -chamber view, $L A$ area $4 c h$ Left atrial area from 4-chamber view, $L A$ length 4ch Left atrial length from 4-chamber view, $L A$ vol Left atrial volume, LAVI Left atrial volume index, NA Not available

control subjects. In that study, restrictive LV filling abnormalities were found in $7.9 \%(7 / 88)$ of patients (defined as increased E/A ratio, decreased DT, decreased S/ D ratio [systolic to diastolic forward flow from pulmonary vein Doppler], and increased atrial reverse flow velocity [from pulmonary vein Doppler] with abnormal LV inflow and pulmonary vein flow patterns. None of those patients had abnormal relaxation (E/A ratio $<1$ and prolonged isovolumic relaxation time). The prevalence of restrictive filling pattern was less than that found in our study (12\%; $14 / 116$ patients). This might be due to differences in diastolic dysfunction grading criteria between studies. Kremastinos, et al. used only restrictive filling pattern, which is the most severe form of diastolic dysfunction. The range of E/A ratio and DT in that study between the restrictive and non-restrictive groups was $2.12-4.14$ vs. $1.06-2.14$ and $105-125 \mathrm{~ms}$ vs. $120-190 \mathrm{~ms}$, respectively. When these values (E/A ratio $\geq 2.12$ and DT $\leq 125 \mathrm{~ms}$ ) were used for diagnosis of restrictive filling pattern in our study, we found a prevalence was 5\% (6/ 116 patients), which is close to that reported by Kremastinos, et al.

Spirito, et al. [8] reported the result of LV diastolic function assessed by TTE among 32 patients with thalassemia major with normal LV systolic function compared to 32 age and gender-matched normal subjects. In the patient group, there was significantly increased $\mathrm{E}$ wave, E/A ratio, and EF slope [rate of deceleration of flow velocity from the early diastolic peak (E)], and decreased DT, each of which reflecting a restrictive filling pattern [31-33]. That group used rather loose criteria, since any patient who had values of any one of these parameters beyond the 95\% confidence limits of the control subjects were defined as abnormal diastolic function, which was demonstrated in $50 \%(16 / 32)$ of patients. As such, the high prevalence of LVDD in the Spirito, et al. study may be explained by differences in the diagnostic criteria between our study and theirs.

The relationship between CMR estimation of myocardial iron and LV systolic and diastolic function was studied in 24 transfusion-dependent thalassemia (TDT) patients with 47 paired TTE and CMR by Leonardi, et al. [9]. In that study, LVDD was defined, as follows: restrictive if $\mathrm{E} / \mathrm{A}>1.5$ and $\mathrm{DT}<140$, impaired relaxation if $\mathrm{E} / \mathrm{A} \leq 0.75$, and pseudonormalization if $0.75<\mathrm{E} / \mathrm{A}<$ 1.5 and DT $>140$ and E/E' $>10$. LV systolic function was evaluated by TTE and CMR. LV systolic function was normal in 32 cases by TTE and in 33 cases by CMR, mild dysfunction (LVEF: 41-55\%) in 9 cases by TTE and in 7 cases by CMR, moderate dysfunction (LVEF: 31$40 \%$ ) in 4 cases by TTE and in 6 cases by CMR, and severe dysfunction (LVEF: $\leq 30 \%$ ) in 2 cases by TTE and in 1 case by CMR. Myocardial T2* was abnormal $(<20 \mathrm{~ms})$ in 54\% (13/24) of patients, and they found restrictive filling pattern $(\mathrm{E} / \mathrm{A} \geq 1.5$ and $\mathrm{DT}<140)$ in all study patients. We used the same criteria in our study and found a prevalence of restrictive filling pattern of 32\% (37/116 patients), which is far lower than that reported by Leonardi, et al. This difference between studies may be explained by differences in baseline characteristics between the two study populations. Study population in Leonardi's study were more severe disease as compared to patients enrolled in our study since they included patients with LV systolic dysfunction, a higher 
percentage of iron overload cardiomyopathy as shown by an abnormal $\mathrm{T} 2 \%$. In our study, all of the included patients had normal LV systolic function, and cardiac T2* was abnormal in 7.76\% (95\% CI: 3.61-14.22\%).

We proposed a CMR criteria for the detection of LVDD modified from the ASE 2009 criteria [28], which focused on parameters on mitral valve filling, and LAVI as suggested by the ASE 2016 criteria [29]. We believed that many thalassemia patients were serially referred to CMR for the assessment of iron overload without request for echocardiogram. It would be better if we can assess cardiac iron overload, left ventricular systolic and diastolic function in the same setting with CMR.. E/A ratio, peak $\mathrm{E}$ velocity, deceleration time to grade LVDD in both ASE 2009 and current 2016 ASE guidelines. However, in 2016 ASE guideline, additional echocardiographic criteria were introduced (E/e', peak TR velocity and LAV index) and some parameters are not available by CMR.

Previous data on prevalence of LVDD in patients with normal left ventricular systolic function showed that if we used the stringent criteria (only restrictive filling as reported by Kremastinos, et al), the prevalence would be $7.9 \%$ but is we used the loose criteria (any one of E, E/a, EF slope, or deceleration time being abnormal as reported by Spirito, et al), the prevalence would be $50 \%$. The prevalence in our report should be more reasonable because our proposed CMR criteria are not too stringent and not too loose.

Age, obesity, and hypertension are known to be associated with diastolic dysfunction [34, 35]; however, the factors associated with LVDD in thalassemia major patients are not well defined. The main factors that were associated with LVDD were homozygous beta-thalassemia and splenectomy. Patients with homozygous beta-thalassemia had the risk of LVDD of $50 \%$ whereas beta-thalassemia/ $\mathrm{Hb} \mathrm{E}$ had the risk of LVDD of $17 \%(p=0.004)$. Patients with splenectomy had the risk of LVDD of 36\% compared to the risk of $16 \%$ for those without splenectomy ( $p=$ 0.024). When we combined the effect of these 2 factors, patients with beta-thalassemia/Hb E and no splenectomy had the risk of LVDD of $12 \%$. The risk increased to 30,44 and $60 \%$ for beta-thalassemia/Hb E with splenectomy, homozygous beta-thalassemia without splenectomy and homozygous beta-thalassemia with splenectomy respectively. The effect of splenectomy and homozygous betathalassemia on the prevalence of LVDD was mainly in population without cardiac iron overload since our population were well treated with chelation therapy. No correlation was found between LV diastolic function and cardiac $\mathrm{T}_{2}$. The prevalence of abnormal cardiac $\mathrm{T} 2 *$ defined as lower than $20 \mathrm{~ms}$ was only $8 \%$ which is too small to make conclusion for the relation of cardiac iron overload and LVDD and other factors. However, when we looked at data of 4 patients with severe cardiac iron overload (defined as cardiac T2* less than $10 \mathrm{~ms}$ ), the prevalence of LVDD in this group was 50\% which is much higher than $20 \%$ those with cardiac $\mathrm{T}^{*}$ less than $10 \mathrm{~ms}$ but the number is too small to achieve statistical significance. Patients with homozygous beta-thalassemia had an increased risk of cardiac iron overload compared to betathalassemia/Hb E ( $21 \%$ vs $6 \%, p=0.041)$. Patients with splenectomy also had an increased trend of cardiac iron overload $(11 \%$ vs $7 \%, \mathrm{p}=\mathrm{NS})$. Splenectomy results in loss of function to remove hematologic debris and to suppress intravascular hemolysis, which leads to increased oxidation, procoagulative state, vasoconstricting substances, smooth muscle proliferation, and endothelial dysfunction [36]. As an alternative to the propose mechanism of iron overload cardiomyopathy only, the mechanism of LVDD in thalassemia major may be due to these pathology in splenectomy patients. Association between homozygous beta thalassemia and LVDD could be explained by splenectomy, which was performed in patients with homozygous beta thalassemia more than in patients with $\mathrm{Hb} \mathrm{E} /$ beta-thalassemia. Both homozygous beta-thalassemia and splenectomy reflect a more severe disease that could lead to LVDD despite no evidence of cardiac iron overload detected by cardiac $\mathrm{T} 2 *$. Therefore, even in patients without detectable cardiac iron overload, LVDD should be looked for in order to detect early cardiac involvement. Early treatment may be possible.

Decrease in BSA associated with more LVDD. BSA may reflect a patient's nutritional status, since vitamin $B$, vitamin $\mathrm{D}$, and carnitine deficiency were reported to be associated with impaired cardiac function [30]. HR and DBP were also associated with LVDD, but the mechanism could not be defined. The following theory might explain the association of low DBP and LVDD. As arterial stiffness increases, the pulse wave velocity along the aorta increases, so that the reflected pulse wave arrives earlier at the ascending aorta and augments the latesystolic ascending aortic pressure waveform and decrease diastolic pressure [37]. Furthermore, late systolic arterial load to the left ventricle, which results in deteriorated left ventricular relaxation [38]. Low DBP has been reported in patients with beta-thalassemia major compared to controls [39]. It has also been reported in other hemolytic disease such as sickle cell anemia [40]. They also measured aortic stiffness parameters and found an increased aortic stiffness in patients with low DBP just like what we just mentioned. An abnormality in autonomic balance as measured by heart rate variability indicated an increase in vagal tone was also demonstrated which may be related to a decrease heart rate in patients with LVDD [39].

This study has some limitations. First, we cannot extrapolate the results since we enrolled only thalassemia patients who were requested for cardiac T2*. Second, we 
did not have echocardiographic data to correlate with CMR findings in every patient. We have echocardiographic data in only 19 patients. Although echocardiogram and CMR was not performed on the same day, we could demonstrate a good correlation with CMR for the detection and grading of diastolic dysfunction in $89.5 \%$. $\mathrm{E}$ and $\mathrm{A}$ values had moderate positive relationship between TTE and CMR methods. Both E and A values from TTE were higher than those measured by CMR, which is similar to previous study [24]. A strong positive relationship was observed between E/A ratio and LAVI. Third and last, mitral valve flow measurement by CMR may yield lower values for the $\mathrm{E}$ and $\mathrm{A}$ parameters than those reported in echocardiographic studies, because of the method of velocity measurement might not be at the tip of the mitral valve.

Further prospective studies of the left ventricular diastolic function by CMR and the cardiac iron overload in various stages of the disease since diagnosis and follow up during treatment may yield more understanding of the disease physiology. Future research for the effect of early detection and treatment on the progression of disease and prognosis is encouraged.

\section{Conclusion}

LVDD already exists from the early stages of the disease before the abnormal heart T2 * is detected. Homozygous beta-thalassemia and splenectomy were strong predictors of LVDD. These data may increase awareness of the disease, especially in the high risk groups.

\section{Abbreviations}

Cl: Confidence interval; CMR: Cardiac magnetic resonance; DBP: Diastolic blood pressure; DT: Deceleration time; EPFR: Early peak filling rate; HR: Heart rate; ICC: Intraclass correlation coefficient; LA: Left atrial; LAVI: Left atrial volume index; LPFR: Late peak filling rate; LV: Left ventricular; LVDD: Left ventricular diastolic dysfunction; OR: Odds ratio

\section{Acknowledgements}

Not Applicable

\section{Authors' contributions}

BC, RK, NR - study conception and design, data acquisition, data interpretation, manuscript preparation, and manuscript revision; YK, PS, W data interpretation and manuscript revision; KK - statistical analysis, data interpretation, and manuscript revision. All authors read and approved the final manuscript.

\section{Funding}

This study was supported by a Siriraj Grant for Research Development (grant no. R15433024). The funding body has not involved in any parts of the design of the study and collection, analysis and interpretation of data and in writing the manuscript.

\section{Availability of data and materials}

The dataset that was used to support the conclusion of this study is included within the manuscript. Any additional data will be made available upon the request to Rungroj Krittayaphong at rungroj.kri@mahidol.ac.th.

\section{Ethics approval and consent to participate}

The study protocol was approved by the Siriraj Institutional Review Board (SIRB), Faculty of Medicine Siriraj Hospital, Mahidol University, Bangkok,

Thailand. Written informed consent was obtained from all included patients.

\section{Consent for publication}

Not applicable.

\section{Competing interests}

The authors declare that they have no competing interests relating to any aspect of this study.

\section{Author details}

${ }^{1}$ Division of Cardiology, Department of Medicine, Faculty of Medicine, Siriraj Hospital, Mahidol University, 2 Wanglang Road, Bangkoknoi, Bangkok 10700, Thailand. 'Department of Medicine, Faculty of Medicine, Siriraj Hospital, Mahidol University, Bangkok, Thailand. ${ }^{3}$ Department of Radiology, Faculty of Medicine, Siriraj Hospital, Mahidol University, Bangkok, Thailand. ${ }^{4}$ Division of Hematology and Oncology, Department of Pediatrics, Faculty of Medicine, Siriraj Hospital, Mahidol University, Bangkok, Thailand.

Received: 31 January 2019 Accepted: 24 October 2019

Published online: 06 November 2019

\section{References}

1. Pennell DJ, Udelson JE, Arai AE, Bozkurt B, Cohen AR, Galanello R, Hoffman TM, Kiernan MS, Lerakis S, Piga A, et al. Cardiovascular function and treatment in beta-thalassemia major: a consensus statement from the American Heart Association. Circulation. 2013;128(3):281-308.

2. Kremastinos DT, Farmakis D, Aessopos A, Hahalis G, Hamodraka E, Tsiapras $D$, Keren A. Beta-thalassemia cardiomyopathy: history, present considerations, and future perspectives. Circ Heart Fail. 2010;3(3):451-8.

3. Somaratne JB, Whalley GA, Poppe KK, Gamble GD, Doughty RN. Pseudonormal mitral filling is associated with similarly poor prognosis as restrictive filling in patients with heart failure and coronary heart disease: systematic review and meta-analysis of prospective studies. J Am Soc Echocardiogr. 2009;22(5):494-8.

4. Somaratne JB, Whalley GA, Gamble GD, Doughty RN. Restrictive filling pattern is a powerful predictor of heart failure events postacute myocardial infarction and in established heart failure: a literature-based meta-analysis. J Card Fail. 2007;13(5):346-52.

5. Hurrell DG, Oh JK, Mahoney DW, Miller FA Jr, Seward JB. Short deceleration time of mitral inflow E velocity: prognostic implication with atrial fibrillation versus sinus rhythm. J Am Soc Echocardiogr. 1998:11(5):450-7.

6. Kremastinos DT, Farmakis D. Iron overload cardiomyopathy in clinical practice. Circulation. 2011;124(20):2253-63.

7. Kremastinos DT, Tsiapras DP, Tsetsos GA, Rentoukas El, Vretou HP, Toutouzas PK. Left ventricular diastolic Doppler characteristics in beta-thalassemia major. Circulation. 1993;88(3):1127-35.

8. Spirito P, Lupi G, Melevendi C, Vecchio C. Restrictive diastolic abnormalities identified by Doppler echocardiography in patients with thalassemia major. Circulation. 1990;82(1):88-94.

9. Leonardi B, Margossian R, Colan SD, Powell AJ. Relationship of magnetic resonance imaging estimation of myocardial iron to left ventricular systolic and diastolic function in thalassemia. JACC Cardiovasc Imaging. 2008;1(5):572-8

10. Westwood MA, Wonke B, Maceira AM, Prescott E, Walker JM, Porter JB, Pennell DJ. Left ventricular diastolic function compared with $T 2^{*}$ cardiovascular magnetic resonance for early detection of myocardial iron overload in thalassemia major. J Magn Reson Imaging. 2005;22(2):229-33.

11. Kremastinos DT, Rentoukas E, Mavrogeni S, Kyriakides ZS, Politis C, Toutouzas P. Left ventricular filling pattern in beta-thalassaemia major--a Doppler echocardiographic study. Eur Heart J. 1993;14(3):351-7.

12. Carpenter JP, Roughton M, Pennell DJ. International survey of T2* cardiovascular magnetic resonance in beta-thalassemia major. Haematologica. 2013;98(9):1368-74.

13. Krittayaphong R, Viprakasit V, Saiviroonporn P, Siritanaratkul N, Siripornpitak S, Meekaewkunchorn A, Kirawittaya T, Sripornsawan P, Jetsrisuparb A, Srinakarin J, et al. Prevalence and predictors of cardiac and liver iron overload in patients with thalassemia: a multicenter study based on realworld data. Blood Cells Mol Dis. 2017;66:24-30. 
14. Karvounis HI, Zaglavara TA, Parharidis GE, Nouskas IG, Hassapopoulou EP, Gemitzis KD, Louridas GE. An angiotensin-converting enzyme inhibitor improves left ventricular systolic and diastolic function in transfusiondependent patients with beta-thalassemia major. Am Heart J. 2001;141(2):281.

15. Kremastinos DT, Tsiapras DP, Kostopoulou AG, Hamodraka ES, Chaidaroglou AS, Kapsali ED. NT-proBNP levels and diastolic dysfunction in betathalassaemia major patients. Eur J Heart Fail. 2007;9(5):531-6.

16. Kinno M, Nagpal P, Horgan S, Waller AH. Comparison of echocardiography, cardiac magnetic resonance, and computed tomographic imaging for the evaluation of left ventricular myocardial function: part 2 (diastolic and regional assessment). Curr Cardiol Rep. 2017;19(1):6.

17. Krittayaphong R, Saiviroonporn P, Boonyasirinant T, Nakyen S, Kangkagate C. Gender differences on the left and right ventricular volume, systolic function and mass assessed by cardiac magnetic resonance imaging. Thai Heart J. 2004;17:171-8.

18. Le TT, Tan RS, De Deyn M, Goh EP, Han Y, Leong BR, Cook SA, Chin CW. Cardiovascular magnetic resonance reference ranges for the heart and aorta in Chinese at 3T. J Cardiovasc Magn Reson. 2016;18:21.

19. He T, Gatehouse PD, Kirk P, Tanner MA, Smith GC, Keegan J, Mohiaddin RH, Pennell DJ, Firmin DN. Black-blood T2* technique for myocardial iron measurement in thalassemia. J Magn Reson Imaging. 2007;25(6):1205-9.

20. Saiviroonporn P, Viprakasit V, Boonyasirinant T, Khuhapinant A, Wood JC, Krittayaphong R. Comparison of the region-based and pixel-wise methods for cardiac T2* analysis in 50 transfusion-dependent Thai thalassemia patients. J Comput Assist Tomogr. 2011;35(3):375-81.

21. Ferguson MR, Otto RK, Bender MA, Kolokythas O, Friedman SD. Liver and heart MR relaxometry in iron loading: reproducibility of three methods. J Magn Reson Imaging. 2013;38(4):987-90.

22. Anderson LJ, Holden S, Davis B, Prescott E, Charrier CC, Bunce NH, Firmin DN, Wonke B, Porter J, Walker JM, et al. Cardiovascular T2-star (T2*) magnetic resonance for the early diagnosis of myocardial iron overload. Eur Heart J. 2001;22(23):2171-9.

23. Krittayaphong R. MRI in thalassemia. In: Boonyasirinant T, Krittayaphong R, editors. Cardiac MRI. Bangkok: Parbpim; 2015. p. 370-95.

24. Rathi VK, Doyle M, Yamrozik J, Williams RB, Caruppannan K, Truman C, Vido D, Biederman RW. Routine evaluation of left ventricular diastolic function by cardiovascular magnetic resonance: a practical approach. J Cardiovasc Magn Reson. 2008;10:36.

25. Brandts A, Bertini M, van Dijk EJ, Delgado V, Marsan NA, van der Geest RJ, Siebelink HM, de Roos A, Bax JJ, Westenberg JJ. Left ventricular diastolic function assessment from three-dimensional three-directional velocityencoded MRI with retrospective valve tracking. J Magn Reson Imaging. 2011:33(2):312-9.

26. Kawaji K, Codella NC, Prince MR, Chu CW, Shakoor A, LaBounty TM, Min JK, Swaminathan RV, Devereux RB, Wang Y, et al. Automated segmentation of routine clinical cardiac magnetic resonance imaging for assessment of left ventricular diastolic dysfunction. Circ Cardiovasc Imaging. 2009;2(6):476-84

27. Mendoza DD, Codella NC, Wang Y, Prince MR, Sethi S, Manoushagian SJ, Kawaji K, Min JK, LaBounty TM, Devereux RB, et al. Impact of diastolic dysfunction severity on global left ventricular volumetric filling - assessment by automated segmentation of routine cine cardiovascular magnetic resonance. J Cardiovasc Magn Reson. 2010;12:46.

28. Nagueh SF, Appleton CP, Gillebert TC, Marino PN, Oh JK, Smiseth OA, Waggoner AD, Flachskampf FA, Pellikka PA, Evangelista A. Recommendations for the evaluation of left ventricular diastolic function by echocardiography. J Am Soc Echocardiogr. 2009;22(2):107-33.

29. Nagueh SF, Smiseth OA, Appleton CP, Byrd BF 3rd, Dokainish H, Edvardsen T, Flachskampf FA, Gillebert TC, Klein AL, Lancellotti P, et al. Recommendations for the evaluation of left ventricular diastolic function by echocardiography: an update from the American Society of Echocardiography and the European Association of Cardiovascular Imaging. J Am Soc Echocardiogr. 2016;29(4):277-314.

30. Tsang TS, Barnes ME, Gersh BJ, Bailey KR, Seward JB. Left atrial volume as a morphophysiologic expression of left ventricular diastolic dysfunction and relation to cardiovascular risk burden. Am J Cardiol. 2002;90(12):1284-9.

31. Appleton CP, Hatle LK, Popp RL. Demonstration of restrictive ventricular physiology by Doppler echocardiography. J Am Coll Cardiol. 1988;1 1(4):757-68.

32. Nishimura RA, Holmes DR Jr, Reeder GS, Tajik AJ, Hatle LK. Doppler echocardiographic observations during percutaneous aortic balloon valvuloplasty. J Am Coll Cardiol. 1988;11(6):1219-26.
33. Valantine HA, Appleton CP, Hatle LK, Hunt SA, Billingham ME, Shumway NE, Stinson EB, Popp RL. A hemodynamic and Doppler echocardiographic study of ventricular function in long-term cardiac allograft recipients. Etiology and prognosis of restrictive-constrictive physiology. Circulation. 1989;79(1):66-75.

34. Fischer M, Baessler A, Hense HW, Hengstenberg C, Muscholl M, Holmer S, Doring A, Broeckel U, Riegger G, Schunkert H. Prevalence of left ventricular diastolic dysfunction in the community. Results from a Doppler echocardiographic-based survey of a population sample. Eur Heart J. 2003; 24(4):320-8.

35. Klapholz M, Maurer M, Lowe AM, Messineo F, Meisner JS, Mitchell J, Kalman J, Phillips RA, Steingart R, Brown EJ Jr, et al. Hospitalization for heart failure in the presence of a normal left ventricular ejection fraction: results of the New York heart failure registry. J Am Coll Cardiol. 2004;43(8):1432-8.

36. Wood JC. Cardiac complications in thalassemia major. Hemoglobin. 2009; 33(Suppl 1):S81-6.

37. O'Rourke MF, Mancia G. Arterial stiffness. J Hypertens. 1999;17(1):1-4.

38. Hori M, Inoue M, Kitakaze M, Tsujioka K, Ishida Y, Fukunami M, Nakajima S, Kitabatake A, Abe H. Loading sequence is a major determinant of afterloaddependent relaxation in intact canine heart. Am J Physiol. 1985;249(4 Pt 2): H747-54.

39. Veglio F, Melchio R, Rabbia F, Molino P, Genova GC, Martini G, Schiavone D, Piga A, Chiandussi L. Blood pressure and heart rate in young thalassemia major patients. Am J Hypertens. 1998;11(5):539-47.

40. Pikilidou M, Yavropoulou M, Antoniou M, Papakonstantinou E, Pantelidou D, Chalkia P, Nilsson P, Yovos J, Zebekakis P. Arterial stiffness and peripheral and central blood pressure in patients with sickle cell disease. J Clin Hypertens (Greenwich). 2015;17(9):726-31.

\section{Publisher's Note}

Springer Nature remains neutral with regard to jurisdictional claims in published maps and institutional affiliations.
Ready to submit your research? Choose BMC and benefit from:

- fast, convenient online submission

- thorough peer review by experienced researchers in your field

- rapid publication on acceptance

- support for research data, including large and complex data types

- gold Open Access which fosters wider collaboration and increased citations

- maximum visibility for your research: over $100 \mathrm{M}$ website views per year

At BMC, research is always in progress.

Learn more biomedcentral.com/submissions 